\title{
Personagens em migração nas adaptações de literatura para cinema: reflexões a partir de 0 Homem Duplicado e de Enemy
}

\author{
Eduardo Nunes \\ Universidade de Aveiro
}

Resumo: Reconhecendo a preponderância das personagens na conformação e comunicação dos sentidos mais relevantes das narrativas a que pertencem, estudar a adaptação entre literatura e cinema - como forma de relacionamento entre narrativas, textos e meios - passa por avaliar as transformações operadas sobre essas figuras aquando do seu trânsito intertextual e intermediático. Neste artigo, partindo do relógio da personagem desenhado por Jens Eder (2010), propomo-nos analisar como as personagens adaptadas e adaptantes convergem e divergem em cada uma das suas quatro componentes: enquanto artefactos, seres ficcionais, símbolos e sintomas.

Palavras-chave: adaptação, personagem, literatura, cinema, estudos interartes

\begin{abstract}
Acknowledging the preponderance of characters in the conformation and configuration of the most relevant meanings of the narratives to which they belong, in order to study literature to film adaptation - as a relationship between narratives, texts and media - one must assess those characters' transformations at the time of their intertextual and intermedial transit. In this article, based on the clock of character designed by Jens Eder (2010), we propose to analyse how adapted and adapting characters converge and diverge regarding each of their four components: as artifacts, fictional beings, symbols and symptoms.
\end{abstract}

Keywords: adaptation, character, literature, film, interart studies 


\section{A personagem e a adaptação: considerações iniciais}

A adaptação fílmica de obras literárias situa-se na interseção de dois campos vastos: o da adaptação, que pode processar-se entre trabalhos pertencentes a quaisquer meios artísticos (ou até a um mesmo), e o das relações entre literatura e cinema, as quais transcendem as ocorrências adaptativas para incluir manifestações de contaminação semiótica ou de permuta estilístico-compositiva entre as duas artes. Em ambos os terrenos, a adaptação de literatura para cinema tem merecido considerações e análises próprias e individualizadas. Assim é, no âmbito dos estudos de adaptação, por ser essa a orientação que o fenómeno adaptativo mais frequentemente assume: partir da literatura para chegar ao cinema. E assim é, também, no quadro das relações interartísticas entre os dois meios, devido às particularidades que essa modalidade de relacionamento arroga e que a distinguem dos demais vínculos: desde logo, trata-se de uma relação abertamente declarada, em que o trabalho adaptante por norma reconhece que é uma adaptação de um texto pré-existente, que identifica; por essa razão, desnuda-se prontamente a natureza relacional na base daquele novo trabalho, a qual vem a ter impactos não só na sua produção, na medida em que ele nasce do conteúdo colhido de uma obra prévia, como ainda na sua receção, visto que as exegeses produzidas por um espetador conhecedor do textofonte tenderão a diferir das que vierem a ser produzidas por quem lide apenas com o trabalho adaptante; e, por último, deve admitir-se que a transcodificação intersemiótica, em que se resolvem tantas manifestações interartísticas (ou, pelo menos, aquelas que ultrapassam a referência direta e explícita a outro meio), se deteta na adaptação apenas ao nível do conteúdo diegético que transita, sujeito a excisões e acrescentos, do trabalho adaptado para o adaptante. Na adaptação entre literatura e cinema, estão, pois, em contacto narrativas, textos e meios diversos, por aí compreendendo-se a confluência nos estudos de adaptação de propostas teoréticas, analíticas e metodológicas de orientação narratológica, intertextual e intermediática (cf. Murray 2008: 5-7; Leitch 2017: 2-5).

Não deve entender-se, porém, que as eventuais diferenças detetadas entre as obras adaptada e adaptante resultam inteiramente do novo molde (ou ambiência mediática) em que se procura encaixar uma dada história. 0 mesmo é dizer: não devem entender-se as 
divergências entre o texto adaptado e a adaptação como decorrentes apenas das especificidades mediáticas e/ou narrativas da literatura e do cinema. É que, para além dos inevitáveis esforços de conformação a um novo meio de uma história que lhe pode ser variavelmente avessa - dir-se-ia, variavelmente (in)adaptável -, influem ainda na configuração final do relato adaptante, com estimável preponderância, as decisões criativas dos respetivos adaptadores. Estas, por sua vez, podem advir de uma certa leitura do texto adaptado, que os adaptadores se propõem, porventura, afunilar ou expandir em filme. Mas elas podem resultar, de igual modo, da vontade de impressão de novos sentidos, ausentes da (ou não tão salientes na) economia significativa da obra primeira, por parte dos adaptadores, assim tornados autores e não meros reprodutores:

The adapted text, therefore, is not something to be reproduced, but rather something to be interpreted and recreated, often in a new medium. [...] the adapter is an interpreter before becoming a creator. But the creative transposition of an adapted work's story and its heterocosm is subject not only to genre and medium demands, [...] but also to the temperament and talent of the adapter - and his or her individual intertexts through which are filtered the materials being adapted. (Hutcheon 2006: 84)

Reconhecendo-se o encontro de subjetividades autorais que preside a um processo adaptativo, ficam demitidas, por conseguinte, as demandas de fidelidade à letra ou ao espírito do texto adaptado: a primeira forma de exigência ignora as diferenças ineludíveis entre o meio literário e o fílmico, as quais, não obrigando necessariamente à excisão de certos conteúdos aquando do trânsito interartístico, podem vir a requerer uma sua reconfiguração inventiva e transformadora; a segunda, concernente ao respeito pelo significado literário do texto adaptado, "supõe um monolitismo interpretativo, em que a verdade inequívoca e unívoca dos textos existisse e fosse captável em exegeses correctas e ortodoxas, ao arrepio da poli-isotopia e plurissignificância destes" (Sousa 2001: 32). Tomando a aferição da (in)fidelidade não enquanto critério avaliativo dos méritos de uma adaptação, mas, ao invés, como uma inevitabilidade quer na receção quer no estudo desse tipo de trabalhos, tendo em conta a natureza relacional que (também) os define, tender-se-á 
a aceitar que o fenómeno adaptativo constitui uma relação interartística de (re)criação e (re)invenção de sentidos, mais do que de contaminação semiótica.

Ora, preponderantes na construção progressiva dos sentidos das narrativas são os seres que as povoam e asseguram o seu desenrolar. As personagens, também por se constituírem como "eixo em torno do qual gira a ação", adquirem uma "relevância funcional e semântica" (Reis 2018: 390, 389), podendo concentrar ou transmitir significados muito diversos:

thematic statements or questions; human properties, problems, virtues and vices (e.g., the evil); abstract ideas or intangible phenomena (e.g., personifications of death); latent meanings in a psychoanalytical sense (suppressed wishes or fears); membership in social groups and roles, as well as archetypes; references to real persons (in the case of key characters) or to characters of the artistic tradition (in the case of intertextual characters). [...] The topics of narratives and other artworks tend to be linked to the properties, values, conflicts, needs, weaknesses or developments of characters; conversely, characters give relevance and unity to stories or artworks as a whole. Moreover, they are one of their most important sources of recipients' responses. (Eder et alii 2010: 46)

Por esse motivo, para avaliar a (re)criação de sentidos que uma certa adaptação opera com respeito ao texto transposto, cabe olhar, antes de mais, às transformações que ela concretiza sobre as personagens adaptadas, redefinindo-lhes alguns contornos ou atributos e, possivelmente, o alcance semântico-pragmático. Serão as alterações que elas vêm a evidenciar na sua transposição fílmica que, em grande parte (embora não exclusivamente), vêm a determinar as eventuais inflexões de significação do trabalho adaptante em relação ao adaptado.

Para uma análise justa e adequada das mutações a que são sujeitas certas personagens num processo transpositivo, cumpre primeiro considerar várias molduras teórico-críticas em que essa categoria da narrativa tem sido enquadrada. Tais modelos teoréticos têm oscilado, com relevantes patamares intermédios, entre a ponderação das figuras ficcionais como entidades mediáticas, que existem apenas nas suas manifestações textuais concretas, e como entidades mentais, ganhando forma nos atos recetivos e perdurando para além deles na imaginação dos recetores (cf. Heidbrink 2010: 70-79). 
Como se compreende, a equação das personagens adaptadas e adaptantes pressupõe, à partida, que elas não existam apenas nos trabalhos específicos em que ocorrem: é a sua capacidade de existência (também) fora dos textos que lhes dão origem que permite o reconhecimento de uma efetiva relação de adaptação entre si. No entanto, é igualmente inegável que o meio, com todo o aparato físico, semiótico e comunicacional que lhe é próprio (cf. Ryan 2012: §1-2), vem a interferir consideravelmente quer na conformação da personagem, quer na sua receção. No caso das adaptações, para retomar algo já destacado, vêm ainda a ter influência na configuração das personagens as opções estilístico-compositivas dos seus criadores primeiros e, depois, na sua deriva intertextual e intermediática, as dos seus adaptadores. As duas conceções de personagem referidas não devem, portanto, ser entendidas em termos antagónicos e inconciliáveis. Ambas compaginam-se numa dinâmica de ambivalência, que Murray Smith explica em termos da twofoldness (ou duplicidade) da personagem: "When we engage with a literary character, our awareness of that character brings together an understanding of their place in the fictional world with an appreciation of their place in the design of the work" (2011: 283) ${ }^{1}$. A figura de ficção é assim vista ora na sua virtualidade representativa (geralmente, de pessoas), ora na sua qualidade de constructo textual.

Para se compreender o que está implicado no processo adaptativo de personagens literárias para cinema, em particular, há que ter em conta a natureza lacunar da sua descrição. Tal incompletude fica a dever-se, por um lado, à condição usual do texto (ou dos textos) como reservatório único de informações sobre a personagem, daí resultando que o que dela se conhece se limita ao que nesse trabalho (ou trabalhos) se afirma e dele (ou deles) se pode deduzir. Por outro, o caráter omisso das figuras é uma consequência dos vazios que o discurso verbal por defeito cria, delegando o seu preenchimento nas receções individuais dos vários leitores. No caso das transposições fílmicas, é aos adaptadores que cabe proceder a esse completamento (já não individual, mas coletivo), constituindo o casting uma das manifestações primeiras e mais notórias dessa tarefa (cf. Reis 2015a: 1516, 33). Porém, a adição de dados - tal como, de resto, a sua excisão ou a sua transformação - vem a verificar-se em vários outros pontos do processo adaptativo, transcendendo a mera 
necessidade imposta pelo salto intermediático das ditas figuras e prendendo-se já com a leitura que os adaptadores fazem do texto adaptado e com aquela(s) que querem plasmar no seu próprio trabalho. Trata-se, pois, de um processo refigurador (cf. Reis 2015a, 2015b) que pode ir além da inevitável doação de contornos físicos precisos às personagens e abranger, de forma ainda mais relevante para a construção dos significados da adaptação, os seus traços psicológicos, actanciais e, por extensão, semânticos.

Pretendendo dar conta das várias camadas de que são feitas - e por meio das quais são compreendidas - as figuras ficcionais, Jens Eder (2010) desenhou um modelo teoréticoanalítico a que deu o nome de clock of character (ou relógio da personagem) ${ }^{2}$. Nele, sintetiza o que entende serem as quatro componentes da personagem: a de artefacto, compreendendo as estratégias estilísticas e compositivas que determinam a sua configuração, os seus modos de representação e a distribuição de informação acerca dela; a de ser ficcional, dizendo respeito às suas propriedades corporais, mentais, sociais e actanciais, em muito responsáveis pela sua aproximação a um ser humano; a de símbolo, concernente aos significados indiretos que dela podem ser inferidos; e a de sintoma, atinente às intenções dos seus criadores e às reações dos seus recetores. A compreensão da personagem em cada uma destas dimensões é auxiliada, por seu turno, pela compreensão cabal das restantes, proporcionando-se assim um entendimento holístico das figuras numa perspetiva comunicacional (desde o momento da produção ao da receção).

Embora não seja esse o seu propósito inicial, o relógio da personagem torna possível uma aquilatação mais justa e acertada dos graus de identidade e alteridade possíveis entre as personagens adaptada e adaptante, permitindo aferi-los com respeito a cada uma das suas diferentes componentes. Propondo-nos fazer justamente isso, tomaremos agora como caso de estudo a adaptação da personagem principal do romance $O$ Homem Duplicado (2002), de José Saramago, em Enemy (2013), filme realizado pelo franco-canadiano Denis Villeneuve e coescrito por si e pelo espanhol Javier Gullón. O processo transpositivo do protagonista romanesco para filme será observado em cada uma das quatro dimensões referidas por Eder: olhando à forma como ele é apresentado num e noutro trabalho; identificando os seus predicados mais relevantes e o seu relacionamento com as demais 
personagens; atentando à sua eventual representatividade de valores ou paradigmas maiores; e vislumbrando os respetivos intuitos autorais (particularmente os dos adaptadores, no que à sua refiguração diz respeito) e os expectáveis impactos recetivos. Por fim, tentaremos avaliar como os resultados dessa análise podem elucidar quanto a aspetos detetáveis em outras refigurações e no fenómeno adaptativo, de forma geral 3 .

\section{O Homem Duplicado e Enemy: um estudo de caso}

Para Enemy, transitaram as traves-mestras do relato romanesco: a narrativa de um professor de História (de nome Tertuliano Máximo Afonso no romance, Adam Bell na adaptação, onde é interpretado por Jake Gyllenhaal) que, certo dia, reconhece num filme um ator exatamente igual a si e decide ir em busca desse duplo (chamado António Claro no romance e Anthony Claire no filme, também interpretado por Gyllenhaal).

Comece-se por atentar na apresentação da personagem, logo no início do texto saramaguiano:

O homem que acabou de entrar na loja para alugar uma cassete vídeo tem no seu bilhete de identidade um nome nada comum, de um sabor clássico que o tempo veio a tornar rançoso, nada menos que Tertuliano Máximo Afonso. Ao Máximo e ao Afonso, de aplicação menos corrente, ainda consegue admiti-los, dependendo, porém, da disposição da espírito em que se encontre, mas o Tertuliano pesa-lhe como uma lousa desde o primeiro dia em que percebeu que o malfadado nome dava para ser pronunciado com uma ironia que podia ser ofensiva. É professor de História numa escola de ensino secundário, e o vídeo tinha-lhe sido sugerido por um colega de trabalho que no entanto não se esquecera de prevenir, Não é nenhuma obra-prima do cinema, mas poderá entretê-lo durante hora e meia. Na verdade, Tertuliano Máximo Afonso anda muito necessitado de estímulos que o distraiam, vive só e aborrece-se, ou, para falar com a exactidão clínica que a actualidade requer, rendeu-se à temporal fraqueza de ânimo ordinariamente conhecida por depressão. Para se ter uma ideia do seu caso, basta dizer que esteve casado e não se lembra do que o levou ao matrimónio, divorciou-se e agora não quer nem lembrar-se dos motivos por que se separou. Em troca não ficaram da mal sucedida união filhos que andassem agora a exigir-lhe grátis o mundo numa bandeja de prata, mas à doce História, a séria e educativa cadeira de História para cujo ensino o chamaram e que poderia ser seu embalador refúgio, vê-a ele desde há muito tempo como uma fadiga sem sentido e um começo sem fim. (Saramago 2003: 11-12) 
Nesta descrição inicial, são prontamente definidos alguns dos atributos mais relevantes do protagonista, os quais vêm a determinar (ou a ser comprovados por) algumas das suas motivações e condutas futuras. Desde logo, destaca-se o seu insólito nome - que, na adaptação, é substituído por um mais corrente e menos excêntrico Adam Bell. Além disso, ele é apresentado no decorrer de uma ação necessária ao desenvolvimento do enredo: o aluguer do filme onde descobrirá o seu duplo, que depois quererá conhecer. E, feito esse enquadramento, são delineados alguns dos seus principais predicados: vive só, sofre de depressão, tida como doença própria dos tempos atuais (os da narrativa, que coincidem com os nossos), é divorciado, não tem filhos e manifesta um cansaço e uma saturação que abrangem mas ultrapassam a sua profissão: o ensino de História numa escola secundária. A solidão, o marasmo e a fadiga parecem contaminar todos os planos "[d]esta maldita rotina, [d] esta repetição, [d]este marcar passo" (idem: 15).

$\mathrm{Na}$ transposição de Villeneuve e Gullón ${ }^{4}$, a vivência monótona de Adam é representada numa sequência de cerca de quatro minutos, inserida numa fase ainda inicial do filme, em que se resumem três dias da sua vida em tudo semelhantes: em todos eles, a personagem leciona uma aula (numa universidade e já não numa escola secundária), ensinando a mesma matéria com palavras semelhantes; viaja para casa, fazendo parte do caminho de transporte público e outra a pé; passa algum tempo sozinha; e recebe em casa a sua namorada, com quem pouco dialoga e se relaciona quase apenas por via sexual. A mesmidade quotidiana é ainda acentuada pela música (também ela iterativa) de Danny Bensi e Saunder Jurriaans que acompanha a sequência, bem como pelo trabalho performativo, nomeadamente corporal e facial, de Gyllenhaal, de que o filme tira proveito através de planos aproximados, de grandes planos e de close-ups.

Contudo, antes disso, Adam é primeiramente apresentado, logo nos planos inaugurais do filme, na sua situação espacial e no seu relacionamento com a mãe. Detenhamo-nos neste segundo ponto, por agora. Ouvimos, então, uma gravação de voz deixada pela mãe da personagem (interpretada por Isabella Rossellini) no atendedor de chamadas do filho, pedindo-lhe que devolva a chamada, o que ele escuta com notório alheamento. É essa uma importante porta de entrada para o contacto com a personagem: a 
aparente desconexão e o desprendimento relacional que marcam a sua vivência, de que também se dá conta no romance. Veja-se o modo como esses traços se verificam nos vários relacionamentos de Adam (e de Tertuliano): com a namorada, Mary (ou Maria da Paz); com o colega (inominado no filme e designado como professor de Matemática no romance); e com a mãe (que no texto adaptado recebe o nome de Carolina Máximo). E note-se, desde já, a supressão, aquando do processo transpositivo, de algumas outras personagens com que Tertuliano Máximo Afonso se relaciona na obra de Saramago: a vizinha do andar de cima, o diretor da escola, algumas colegas e o senso comum, figura frequentemente interventiva.

Da relação de seis meses que Tertuliano Máximo Afonso estabelece com Maria da Paz diz-se que "está para acabar mais dia menos dia" (idem: 121). Ele sente que as horas na companhia da namorada se traduzem em "Tanto tempo perdido" e, "para não se deixar prender demasiado, [mantém] cientemente Maria da Paz à margem da sua vida particular" (idem: 112, 128-129). O vínculo que os une é, da ótica de Tertuliano, orientado, por vezes em termos tensionais, ora pela necessidade de uma companhia no frio e solitário mundo contemporâneo, ora pela resistência quase instintiva a um compromisso sério. Pois leia-se:

A meio da tarde telefonou a Maria da Paz e perguntou-lhe se queria passar por ali quando saísse do banco, ela disse que sim, mas que não poderia demorar-se porque a mãe não se encontrava bem de saúde, e então ele disse-lhe que não viesse, que em primeiro lugar estava a obrigação familiar, e ela insistiu, Ao menos para te ver, e ele concordou, disse, Ao menos para nos vermos, como se ela fosse a mulher amada, e sabemos que não o é, ou talvez o seja e ele não saiba, ou talvez, parou nesta palavra por não saber como poderia terminar honestamente a frase, que mentira ou que fingida verdade iria dizer a si mesmo, é certo que a comoção lhe havia roçado de leve os olhos, ela queria vê-lo, sim, às vezes é bom haver alguém que nos quer ver e o diz, mas a lágrima denunciadora, já enxugada pelas costas da mão, se apareceu foi por ele estar sozinho e porque a solidão, de repente, lhe pesou mais do que nas piores horas. (idem: 201-202)

Também em Enemy, o relacionamento entre Adam e Mary (interpretada por Mélanie Laurent) é marcado pela distância, visível na escassez de falas entre ambos e no pouco interesse que o protagonista demonstra em passar tempo com a namorada, suspirando quando a ouve tocar à campainha de sua casa e preferindo continuar a corrigir exames em 
vez de se juntar a ela na cama. Esse afastamento afetivo é ainda visualmente transmitido, por meio de planos em que as personagens surgem fisicamente distantes uma da outra (figs. 1 e 2).

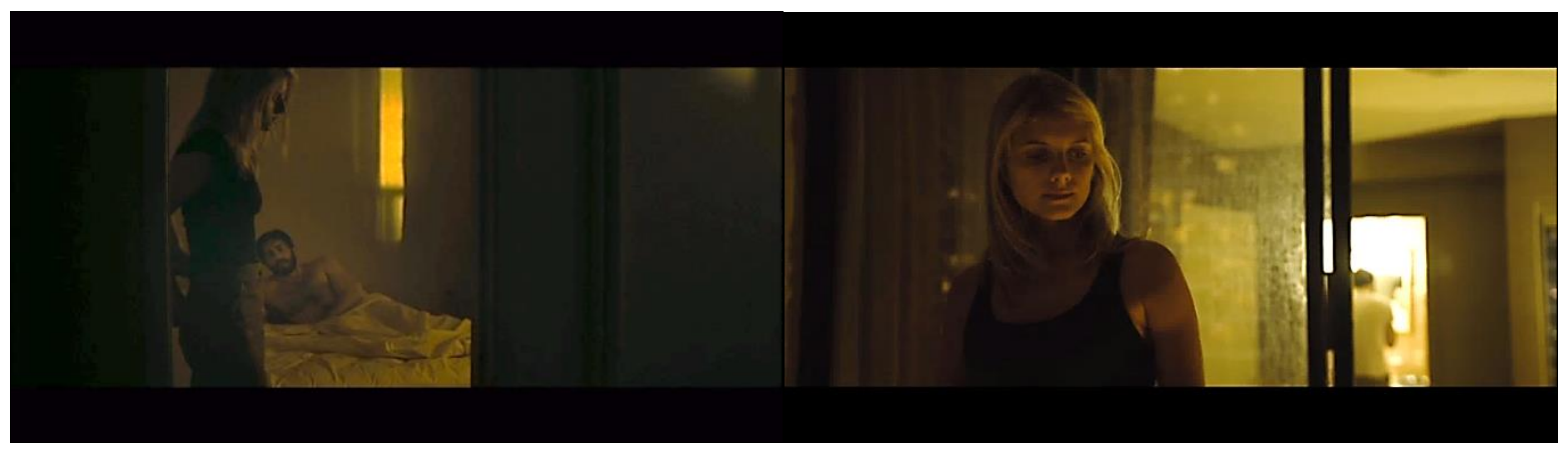

Figuras 1 e 2: evidências de distanciamento entre Adam e Mary (Villeneuve 2014: 08:24, 09:33)

Uma tal separação física e, por extensão, afetiva é ainda representada na cena em que um colega de Adam (interpretado por Joshua Peace), a personagem equivalente à do romanesco professor de Matemática, lhe recomenda um filme, num diálogo também ele pouco desenvolto, especialmente da parte do protagonista (fig. 3).

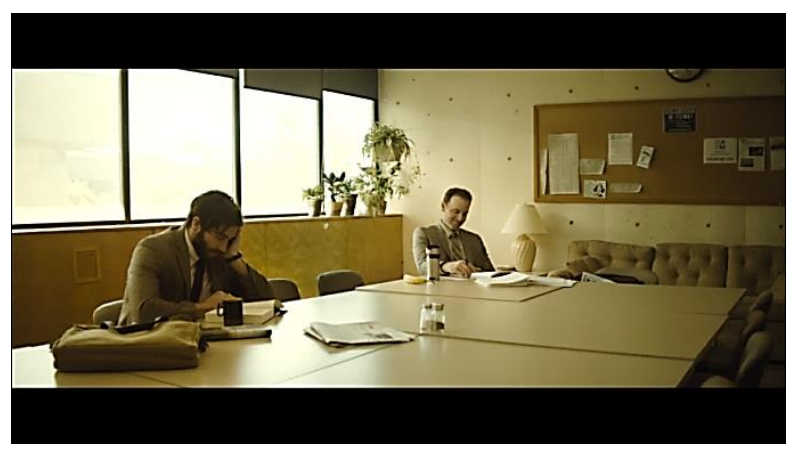

Figura 3: distanciamento físico entre Adam e o seu colega (Villeneuve 2014: 10:22)

No que concerne à ligação de Tertuliano a Carolina Máximo, alude-se no romance à pouca frequência com que aquele lhe telefona, não se esforçando para colmatar a lonjura geográfica que o separa da mãe, uma "Pobre mulher, lá tão longe, sem notícias, e tão discreta e respeitadora da vida do filho" (Saramago 2003: 137). A turbulência relacional entre ambos é ainda mais acentuada no filme, como se pode ver na única cena em que a 
personagem de Isabella Rossellini participa fisicamente e na qual desvaloriza, com certeza e prontidão, os recentes eventos na vida do filho, relativos à descoberta do seu duplo.

Por meio da fragilidade relacional de que Tertuliano e Adam dão mostras, vai sendo desenvolvida, num e noutro trabalho, a linha temática da incomunicabilidade, enquadrada na problemática identitária que o evento da duplicação, por defeito, sinaliza. Tenha-se em conta, a esse respeito, que a debilidade dos vários vínculos românticos, familiares ou sociais de Tertuliano e de Adam é consequência direta da incomunicabilidade, isto é, da incapacidade de abertura de si ao outro. Ora, esse autoisolamento conduz ao desconhecimento do outro, mesmo quando ele parece próximo, e, consequentemente, à ignorância e incompreensão de si próprio - de que acaba por ser exemplo a adoção da identidade dos duplos, quer por Tertuliano, quer por Adam, no final das respetivas narrativas.

Todos esses vetores semânticos adquirem novos contornos quando enraizados numa dada situação temporal: a da contemporaneidade. E, em $O$ Homem Duplicado e em Enemy, essa fixação cronológica é indissociável da fixação espacial das personagens e do enredo numa grande metrópole, o cenário que define prototipicamente a pós-modernidade. Conforme ficou dito acima, a adaptação começa por situar a ação num espaço concreto: a cidade de Toronto, no Canadá (fig. 4).

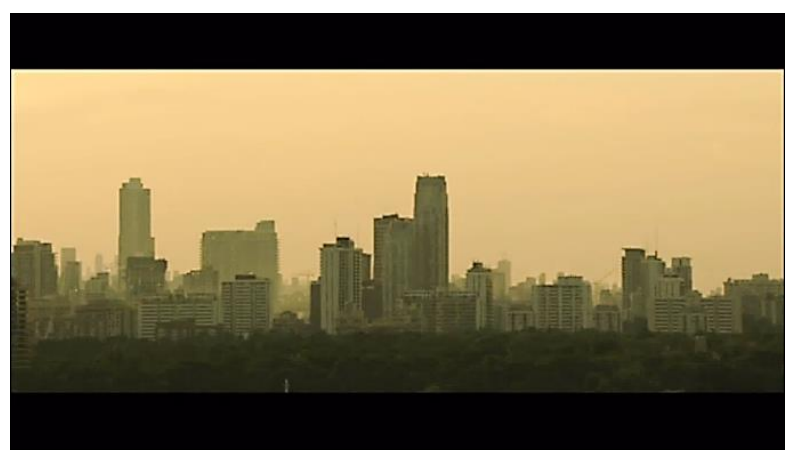

Figura 4: plano inicial de Enemy, em travelling lateral (Villeneuve 2014: 00:43)

De modo diverso, no romance de José Saramago, essa localização espacio-temporal apenas é feita num momento mais adiantado do relato e nos seguintes moldes: 
É a altura de informar aqueles leitores que, ajuizando pelo carácter mais que sucinto das descrições urbanas feitas até agora, tenham criado no seu espírito a ideia de que tudo isto se está a passar numa cidade de tamanho mediano, isto é, abaixo do milhão de habitantes, é a altura de informar, dizíamos, que, muito pelo contrário, este professor Tertuliano Máximo Afonso é um dos cinco milhões e pico de seres humanos que, com diferenças importantes de bem-estar e outras sem a menor possibilidade de mútuas comparações, vivem na gigantesca metrópole que se estende pelo que antigamente haviam sido montes, vales e planícies, e agora é uma sucessiva duplicação horizontal e vertical de um labirinto, de começo agravada por componentes que designaremos por diagonais, mas que, no entanto, com o decorrer do tempo, se revelaram até certo ponto equilibradores da caótica malha urbana, pois estabeleceram linhas de fronteira que, paradoxalmente, em lugar de terem separado, aproximaram. 0 instinto de sobrevivência, também disso se trata quando da cidade falamos, vale tanto para os animais como para os inanimais [...]. (Saramago 2003: 72-73)

Como se constata, o espaço em que decorrem os eventos de $O$ Homem Duplicado é apenas desenhado em traços largos, sem que se individualize a cidade em que decorre a ação. Além desse aspeto, sobressaem dessa primeira (e mais profusa) descrição atributos relevantes para a configuração do cenário romanesco, a saber: o elevado número de residentes nessa cidade, as desigualdades que ela alberga no seu seio e a forma labiríntica e caótica por ela assumida. Em particular, a retenção desta última característica ajuda a compreender a classificação que o narrador faz desse espaço urbano como "modelo perfeito das modernas dificuldades de comunicação" (idem: 206).

$\mathrm{Na}$ transposição fílmica, recorda-se insistentemente aos espetadores qual o local em que se desenrola o fio narrativo, fazendo intercalar várias cenas com planos que apresentam a cidade de Toronto. E essa apresentação não é inócua, pois vai contribuindo para a configuração de uma dada imagem do espaço urbano, que concorre diretamente para a construção ou redefinição dos sentidos mais salientes da obra. Assim, os planos gerais da cidade vão dando conta, para além da vastidão da metrópole, da crescente neblina que circunda os seus edifícios, cujo adensamento acompanha a progressão narrativa e cria uma sensação de desconhecimento e mistério em torno daquele local e, por conseguinte, das vivências que nele decorrem (figs. 5 e 6). De mais a mais, os planos contrapicados com que 
são exibidas várias construções citadinas parecem conceder ao espaço traços de desproporção, monstruosidade e aprisionamento (figs. 7 e 8).

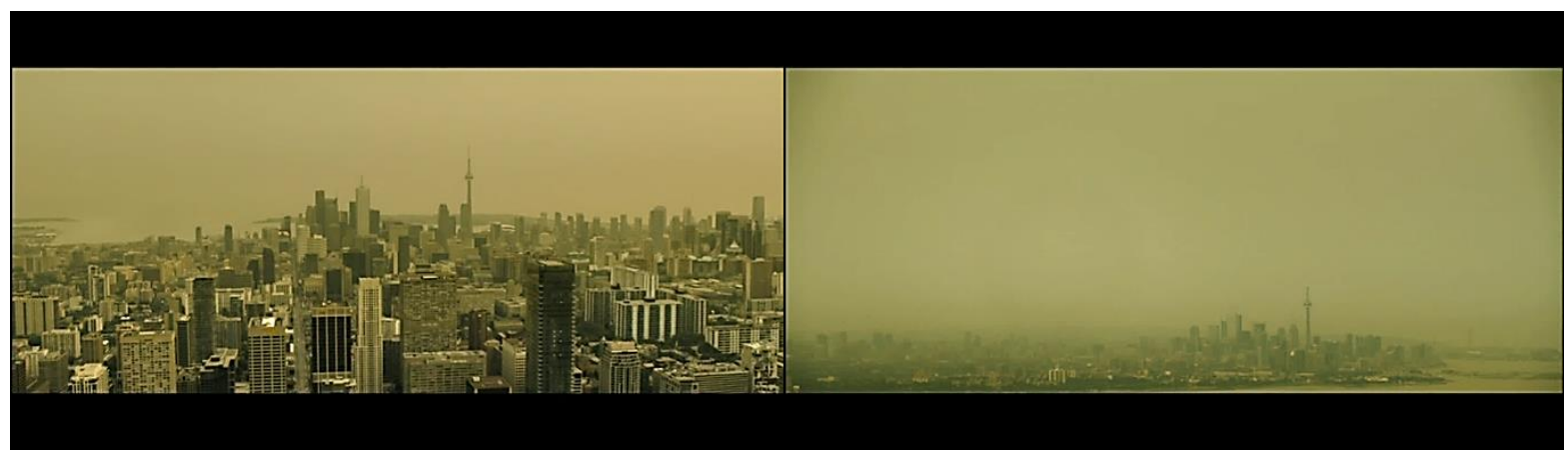

Figuras 5 e 6: planos gerais de Toronto (Villeneuve 2014: 05:23, 01:19:07)

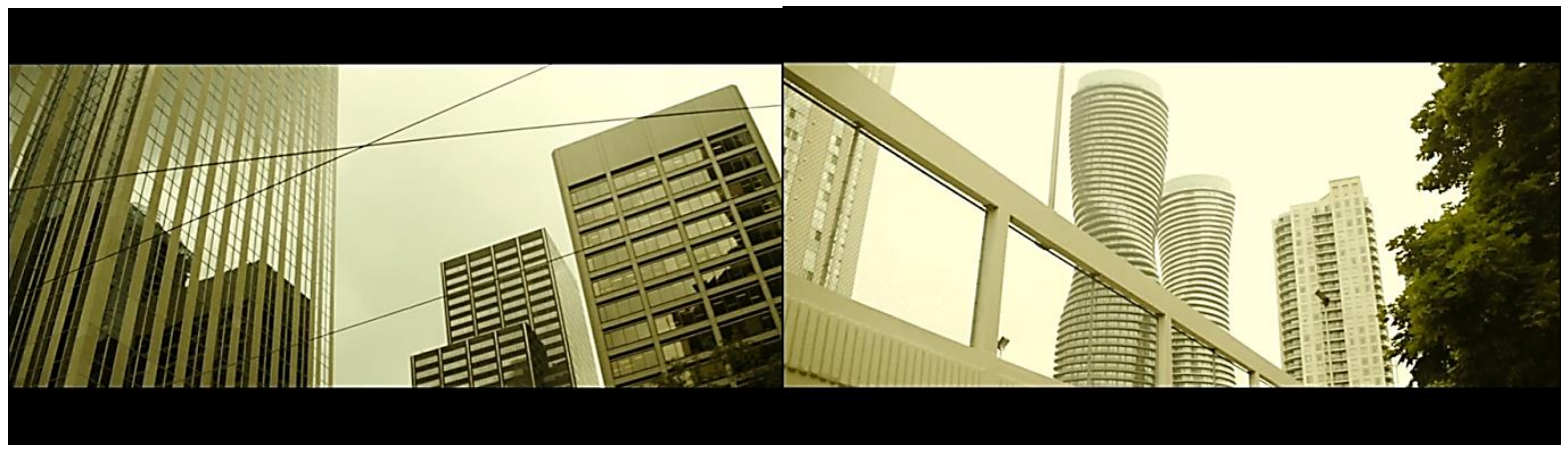

Figuras 7 e 8: planos contrapicados de edifícios urbanos (idem: 25:06, 28:52)

É, pois, num lugar que nos é familiar - mesmo quando não precisado, como sucede no texto adaptado - e num tempo que reconhecemos, porque o habitamos, que se processa o questionamento identitário dos protagonistas de ambos os trabalhos. Nossos conhecidos são, ainda, os temas que do das identidades derivam, próprios da pós-modernidade e dos quais já se tratou acima. E, enfim, porque de Tertuliano Máximo Afonso e de Adam Bell irradiam os vetores temáticos das respetivas obras, eles podem ser vistos como paradigmas do indivíduo contemporâneo.

Com efeito, a duplicação de que são alvo pode ser lida à luz da instabilidade e do fracionamento identitário do sujeito pós-moderno, "composto não de uma única, mas de várias identidades, algumas vezes contraditórias ou não-resolvidas" (Hall 2006: 12). É que, 
nos tempos correntes, a identidade não é já um dado com que cada indivíduo nasce e que este conserva ao longo da sua existência, sem inflexões significativas. Ela está estritamente dependente, agora, do enraizamento histórico-cultural dos sujeitos e, dada a sua provisoriedade, torna-se sujeita a mutações relevantes:

O sujeito assume identidades diferentes em diferentes momentos, identidades que não são unificadas ao redor de um "eu" coerente. Dentro de nós há identidades contraditórias, empurrando em diferentes direções, de tal modo que nossas identificações estão sendo continuamente deslocadas. [...] A identidade plenamente unificada, completa, segura e coerente é uma fantasia. Ao invés disso, à medida em que os sistemas de significação e representação cultural se multiplicam, somos confrontados por uma multiplicidade desconcertante e cambiante de identidades possíveis, com cada uma das quais poderíamos nos identificar - ao menos temporariamente. (idem: 13)

Veja-se, igualmente, como os vínculos românticos de Adam e Tertuliano se compaginam com o que Zygmunt Bauman identificou enquanto marca da experiência amorosa na modernidade líquida: a debilidade, a efemeridade e a leveza dos atuais laços autorizam que, em vez de relacionamentos, se fale em conexões, vendo nessa alteração terminológica um reflexo da maior facilidade e rapidez com que hoje se instauram e cortam elos interpessoais (cf. Bauman 2003: 9-15). O desprendimento com que o protagonista do romance de Saramago encara o seu (des)compromisso com Maria da Paz é exemplo disso ou não estivessem eles numa "ligação sentimental de temporada" (Saramago 2003: 204) -, fazendo com que o próprio narrador hesite na identificação do papel que Tertuliano ocupa na vida da namorada: seja ele "o seu noivo, amante, amigo de cama, ou como quer que se lhe chame nos tempos de hoje" (idem: 66).

Com base nos dados aqui recolhidos, encontramo-nos com condições bastantes para extrair algumas conclusões, aplicáveis tanto a esta transposição fílmica específica quanto, como esperamos, a outras congéneres.

\section{Identidades e alteridades: algumas conclusões possíveis}

Recuperando o relógio da personagem de Eder (2010), e findando o que nos 
propusemos fazer, talvez seja útil avaliar como em cada uma das quatro componentes aí destrinçadas a personagem adaptante (Adam Bell) se aproxima da adaptada (Tertuliano Máximo Afonso), ponderando, de igual forma, em que medida esse caso particular de estudo pode iluminar a compreensão das relações entre as figuras adaptadas e adaptantes, de modo geral.

Antes de qualquer consideração posterior, deve notar-se a diferente natureza mediática e semiótica de que uma e outra são feitas, o que desautoriza, à partida, uma equação da identidade total entre as duas personagens: a sua existência num e noutro trabalho é diversa e dessas diferenças advirão, por sua vez, algumas outras (para além daquelas que os adaptadores decidem, por sua livre vontade, instituir). Essas diferenças ditas inevitáveis, em consequência de estarem em confronto meios diversos, decorrem das particularidades de cada forma artística. Como nota Robert Stam:

Although the novelistic character is a verbal artifact, constructed quite literally out of words, the cinematic character is an uncanny amalgam of photogenic, body movement, acting style, and grain of voice, all amplified and molded by lighting, mise-en-scène, and music. (2000:60)

Encontramo-nos aqui, pois, no domínio da personagem enquanto artefacto. Essa diferença material entre as figuras adaptada e adaptante - isto é, em termos da matéria semiótica de que cada uma é feita - tem uma consequência direta e manifesta: o retrato físico da personagem fílmica é iniludivelmente mais completo do que o da personagem literária. Se assim é sempre, em virtude dos vazios que o discurso verbal cria, também é verdade que esse contraste se torna mais evidente quando o retrato da personagem literária adaptada é francamente lacunar, como no caso em apreço. A esse respeito, dela apenas se diz, em $O$ Homem Duplicado, que tem trinta e oito anos e não tem bigode no tempo atual da narrativa, deixando-se a definição dos restantes contornos corporais a cargo da imaginação dos leitores. Com efeito, um dos impactos primeiros e mais evidentes do trânsito de personagens de um meio eminentemente verbal para um audiovisual é a concretização de aspetos cuja fisicidade literariamente apenas se consegue descrever de forma inacabada, vindo as figuras ficcionais a adquirir os traços corporais e vocais dos 
atores e das atrizes que as interpretam. Trata-se de uma manifestação notória do suplemento inevitável (idem: 55) aportado pelo meio fílmico. No caso das transposições intermediáticas, ele vem a repercutir-se ainda numa (re)leitura do texto adaptado posterior à receção do trabalho adaptante, quando, sobre as descrições verbais das personagens romanescas, se projetam quase instintivamente os contornos concretos dos corpos e das vozes dos atores que as interpretaram (cf. Hutcheon 2006: 22; Reis 2018: 23).

A isso acrescem os contrastes estilístico-compositivos dos autores dos respetivos trabalhos, que se refletem (não só mas também) na configuração dessas personagens. Em particular, influem nesse ponto as decisões criativas dos adaptadores, que podem escolher (e frequentemente escolhem) apresentar a personagem de uma forma diversa daquela por que é dada a conhecer no texto adaptado. Veja-se, no caso em apreço, como na primeira referência a Tertuliano Máximo Afonso se privilegia a abstrusidade do seu nome e, de seguida, se elencam as suas características nucleares. Já Enemy preocupa-se em situar prontamente o seu protagonista no espaço em que se movimenta e em apresentá-lo na sua indiferença relacional. Conclui-se, então, que a distribuição de informação acerca das figuras difere, também, do texto adaptado para a adaptação. Pelas razões aqui apontadas, pode inferir-se que, enquanto artefactos, as personagens adaptada e adaptante divergem forçosamente, atendendo à sua diferente existência mediática, por um lado, e às diversas subjetividades autorais responsáveis pela sua conformação em cada trabalho, por outro.

No que respeita à componente de ser ficcional, algumas divergências são esperadas, desde logo no decurso das diferenças enquanto artefacto: é que, em filme, a personagem adquire, conforme já se notou, características corporais que no livro não são referidas. Mas algumas outras discordâncias emergem, em razão de os adaptadores raramente transporem de modo acrítico aquilo que colhem do texto adaptado. As mais das vezes, ao invés, submetem esse material recolhido a operações transformativas. Isso se constata, também, em O Homem Duplicado e em Enemy: os nomes dos protagonistas diferem; diferente é o seu local de trabalho; e, no atinente aos seus atributos sociais, afere-se que a supressão de personagens romanescas no processo transpositivo para filme resulta numa (ainda maior) escassez de relacionamentos interpessoais na nova narrativa. 
Contudo, cumpre notar que essas alterações não são significativas, na medida em que não interferem com os atributos fundamentais da personagem: ela é, num e noutro trabalho, uma figura solitária, habitante de uma grande cidade, adulta em idade ativa, professora de História, com poucos laços afetivos. São esses os ingredientes que fundamentam, em $O$ Homem Duplicado e em Enemy, o questionamento identitário tal como ele se processa. E, paralelamente, é a sua transferência para a adaptação que faz com que as principais linhas semântico-pragmáticas de uma e de outra obra se aproximem grandemente (mesmo que com pontuais inflexões). Como tal, enquanto seres ficcionais, as personagens adaptada e adaptante tenderão a divergir, de novo por causa da forma crítica como os adaptadores guiam o processo transpositivo; mas as diferenças daí resultantes não deverão ser relevantes, de modo a que se identifique entre uma e outra figura uma efetiva relação adaptativa - isto é, para que se entenda uma como a correspondente da outra, nos seus desenhos narrativos particulares.

Ora, da manutenção dos principais atributos psicológicos e actanciais das personagens advém que, tal como já se indiciou, os sentidos que elas irradiam e/ou que nelas se projetam no romance e no filme tenderão a ser idênticos, quando não coincidentes. Passamos, então, à componente de símbolo.

A título de exemplo, atente-se nos impactos semântico-pragmáticos das mutações acima referidas. A raridade do nome Tertuliano Máximo Afonso pode sinalizar o desajuste dessa personagem em relação ao mundo contemporâneo, cuja frieza e impessoalidade o conduzem a duvidar da sua própria identidade. 0 mesmo sentido não pode ser atribuído ao nome Adam Bell. Porém, se se recordar a virtualidade representativa, por parte de ambas as personagens, do sujeito pós-moderno em situação urbana, pode rastrear-se na maior vulgaridade do nome da personagem fílmica, que não por acaso retoma a designação do protagonista do Génesis bíblico, uma tentativa de acentuar esse seu caráter simbólicoarquetípico. Por sua vez, a decisão de deslocar o local de trabalho do protagonista de uma escola secundária para uma universidade pode ser entendida como tendo o intuito de dotar a personagem e, especialmente, a cidade que ela habita de um maior cosmopolitismo, preponderante, como já se viu, no processamento das questões identitárias. E, por último, 
se os relacionamentos suprimidos na adaptação assinalam, no romance, o circunstancialismo de muitos dos laços sociais de Tertuliano Máximo Afonso - decorrentes da sua situação profissional (diretor e colegas), da sua residência num prédio (vizinha do andar de cima) e da sua inserção numa determinada comunidade (senso comum) -, a sua excisão em Enemy acentua a escassez dos vínculos interpessoais que o protagonista tem. Portanto, essas três transformações criativas, exercidas pelos adaptadores sobre o material colhido, não alteram sobremaneira os significados indiretos que das personagens podem ser inferidos. Em rigor, acentuam alguns outros, já presentes no texto adaptado.

Por fim, chegamos à componente de sintoma. Atendendo às intenções autorais subjacentes aos processos refigurativos das ditas personagens, admitir-se-ão aí diferenças expectáveis, tanto mais compreendidas quanto se tiver em conta o que foi inicialmente referido: que a adaptação se assume como uma relação interartística de (re)criação de sentidos. Assim, aceitando que as figuras ficcionais são elementos importantes na construção e transmissão dos vetores semânticos das narrativas, a reconfiguração daquelas aquando da sua migração intertextual e intermediática é orientada pelo modo como os adaptadores pretendem articular os sentidos presentes no texto adaptado, suprimindo uns, mantendo outros, redefinindo alguns antigos e acrescentando novos. Dessa forma se compreende como Enemy parece trabalhar mais insistentemente uma linha de sentido psicanalítica que O Homem Duplicado apenas deixa sugerida em segundo plano. E a adaptação fá-lo, nesse caso, entre outras estratégias, através de uma transformação subtil da mãe do protagonista, a quem confere um maior poder censório e repressivo do que aquele que tem no romance - quase como se de um superego do filho se tratasse. Analogamente, pode vislumbrar-se na manutenção dos principais predicados de Tertuliano Máximo Afonso em Adam Bell o fito de conservar na adaptação os sentidos maiores da narrativa adaptada: a indagação das identidades, a fragilidade das relações humanas coevas e a interação entre o (des)conhecimento do outro e o (des)conhecimento de si.

Também no tocante às reações que as ditas figuras suscitam nos recetores são expectáveis divergências mais ou menos significativas, ainda que por outra ordem de razões. Decorre essa expectativa do que já se viu serem as incontornáveis diferenças 
semióticas entre as personagens adaptada e adaptante e as lonjuras estilísticas e compositivas entre os respetivos autores. É que, sendo aquelas feitas de materiais distintos e apresentadas por meio de estratégias narrativas diversas, não obstante um não significativo dissenso nas suas propriedades centrais, os respetivos atos de receção tenderão igualmente a divergir. Tomem-se dois exemplos: um leitor do texto adaptado tenderá a valorizar os eventuais significados do nome da personagem, dado que é essa a primeira característica que dela se destaca no romance, onde é sempre referida por meio dos seus três nomes, enquanto no filme não se realça a designação onomástica de Adam Bell; por outro lado, conquanto também seja importante na construção romanesca dos significados em torno do evento nodal da duplicação, a recorrente lembrança ao espetador de que a ação fílmica se desenvolve numa gigantesca metrópole faz com que ele venha a valorizar esse dado na descodificação dos significados mais relevantes de Enemy, previsivelmente mais ainda do que um leitor de $O$ Homem Duplicado valoriza as escassas e esporádicas (mas nem por isso despiciendas) descrições urbanas. Logo, em estreita conexão com a componente de artefacto, também enquanto sintomas as figuras adaptada e adaptante divergirão, parcial ou totalmente.

Em suma, podem sintetizar-se as conclusões aqui expostas no seguinte quadro (fig. 9):

\begin{tabular}{|c|c|c|c|c|}
\hline & \multicolumn{4}{|c|}{ Componentes da personagem (Eder, 2010) } \\
\hline & Artefacto & Ser ficcional & Símbolo & Sintoma \\
\hline $\begin{array}{l}\text { Regimes de } \\
\text { relacionamento } \\
\text { expectáveis entre } \\
\text { personagens adaptadas e } \\
\text { adaptantes em cada uma } \\
\text { das suas componentes: }\end{array}$ & $\begin{array}{l}\neq \\
\text { (diferença) }\end{array}$ & $\begin{array}{l}\approx \\
\text { (proximidade) }\end{array}$ & $\begin{array}{l}=/ \approx \\
\text { (igualdade ou } \\
\text { proximidade) }\end{array}$ & $\begin{array}{l}\approx / \neq \\
\text { (proximidade } \\
\text { ou diferença) }\end{array}$ \\
\hline
\end{tabular}

Figura 9: proposta descritiva da relação entre personagens adaptada e adaptante, no que respeita a cada uma das suas componentes. 
A proposta que aqui apresentamos pretende ser descritiva e não prescritiva, isto é, visa dar conta dos pontos em que as personagens de um texto adaptado e de uma adaptação mais se aproximam e mais se distanciam, nas ocorrências mais frequentes dos fenómenos adaptativos. Ela não deve, pois, ser encarada como barómetro avaliativo dos méritos de um trabalho adaptante. Rejeitou-se uma semelhante normatividade quando se falou de fidelidade e torna-se a rejeitá-la agora, pois negaria as virtualidades artístico-criativas que fazem das adaptações obras esteticamente autónomas e, pode acrescentar-se, dignas de interesse. 0 presente modelo, confessamente devedor do de Jens Eder, intenta tão-somente servir de método de medição da maior proximidade ou distância entre as personagens adaptadas e adaptantes, capaz de elucidar relativamente, também, à maior proximidade ou distância entre os respetivos texto adaptado e adaptação. Ao mesmo tempo, ele ajuda a sinalizar que, mesmo existindo uma apreciável aproximação entre os dois trabalhos, esta nunca chega a adquirir os contornos de uma igualdade completa, visto que algumas mudanças (no caso, atinentes aos seres ficcionais) são inevitáveis.

\section{NOTAS}

1 Conforme se constata, Murray Smith refere-se especificamente à personagem literária. Todavia, a duplicidade que refere parece ser detetável tanto nas figuras literárias, quanto nas fílmicas (ou nas de qualquer outra forma artística).

2 Por seu lado, Eder refere-se, em concreto, à personagem fílmica, mas também neste caso as considerações tecidas são adequadas às figuras construídas nos diferentes meios artísticos. 


\footnotetext{
${ }^{3}$ Naturalmente, uma tal indução de modos de relacionamento genericamente aplicáveis aos vários e prolíferos pares de personagens adaptadas e adaptantes, tendo como referente um único caso de análise, não é isenta de riscos, que aqui reconhecemos. Porém, sem esperar oferecer, com esta pesquisa, dados absolutos e dogmáticos a esse respeito, ela servirá sobretudo para extrair as conclusões possíveis, dotadas, conforme se verá, de uma margem apreciável de oscilação. Partindo do que aqui se exporá, poder-se-á, noutras ocasiões, confirmar a validade dessas ilações, olhando a outros pares de figuras e a outras narrativas, possivelmente até nascidas de relações adaptativas entre outros meios artísticos.

${ }^{4}$ Entendemos como adaptadores tanto o realizador como o (primeiro) argumentista, assim sinalizando a importância do guião enquanto documento que opera as primeiras decisões relativas ao que transita ou não do texto adaptado.
}

\section{Bibliografia}

Bauman, Zygmunt (2003), Amor Líquido. Sobre a Fragilidade dos Laços Humanos, tradução de Carlos Alberto Medeiros, Lisboa, Relógio D’Água.

Eder, Jens (2010), “Understanding characters”, Projections, vol. 4, no 1, 16-40.

Eder, Jens et alii (2010), "Characters in fictional worlds: an introduction", in Characters in Fictional Worlds, Berlin/New York, Walter de Gruyter, 3-64.

Hall, Stuart (2006), A Identidade Cultural na Pós-Modernidade, tradução de Tomaz Tadeu da Silva / Guaracira Lopes Louro, Rio de Janeiro, DP\&A [1992].

Heidbrink, Henriette (2010), "Fictional characters in literary and media studies: a survey of the research", in Characters in Fictional Worlds, Berlin/New York, Walter de Gruyter, 67- 
110.

Hutcheon, Linda (2006), A Theory of Adaptation, New York, Routledge.

Leitch, Thomas (2017), "Introduction", in The Oxford Handbook of Adaptation Studies, New York, Oxford University Press, 1-20.

Murray, Simone (2008), "Materializing adaptation theory: the adaptation industry", Literature/Film Quarterly, vol. 36, nำ 1, 4-20.

Reis, Carlos (2015a), "Estudos narrativos: a questão da personagem ou a personagem em questão", in Pessoas de Livro. Estudos sobre a Personagem, Coimbra, Imprensa da Universidade de Coimbra, 13-41.

-- (2015b), "Pessoas de livro: figuração e sobrevida da personagem", in Pessoas de Livro. Estudos sobre a Personagem, Coimbra, Imprensa da Universidade de Coimbra, 119-143.

-- (2018), Dicionário de Estudos Narrativos, Coimbra, Almedina.

Ryan, Marie-Laure (2012), "Narration in various media", in The Living Handbook of Narratology, Hamburg, Hamburg Univesity, < https://www.lhn.unihamburg.de/node/53.html> (último acesso em 06/07/2019).

Saramago, José (2003), O Homem Duplicado, 2ª ed., Lisboa, Caminho [2002].

Smith, Murray (2011), "On the twofoldness of character”, New Literary History, vol. 42, nำ 2, 277-294.

Sousa, Sérgio Guimarães de (2001), Relações Intersemióticas entre o Cinema e a Literatura. A Adaptação Cinematográfica e a Recepção Literária do Cinema, Braga, Centro de Estudos Humanísticos/Universidade do Minho.

Stam, Robert (2000), "Beyond fidelity and the dialogics of adaptation", in Film Adaptation, New Brunswick, NJ, Rutgers University Press, 54-76.

Villeneuve, Denis (realizador) (2014), O Homem Duplicado [DVD], Lisboa, NOS Audiovisuais [2013]. 
Eduardo Nunes é estudante do Programa Doutoral em Estudos Literários da Universidade de Aveiro. É Mestre em Literatura de Língua Portuguesa pela Faculdade de Letras da Universidade de Coimbra, tendo defendido nesse âmbito a dissertação intitulada Literatura e cinema num jogo (de) duplo(s): o caso da adaptação fílmica de $O$ Homem Duplicado, de José Saramago. É também licenciado em Português com Menor em Estudos Artísticos pela mesma instituição. Tem apresentado comunicações em colóquios locais e internacionais sobre cinema, televisão, estética e literaturas de língua portuguesa. Para além desses campos de interesse, tem desenvolvido investigação na área dos estudos interartes e narrativos. 